Sciendo

\title{
Self-Evidence and A Priori Moral Knowledge
}

\author{
Elizabeth Tropman \\ Colorado State University
}

Disputatio Vol. 4, No. 33

November 2012

DOI: $10.2478 /$ disp-2012-0011

ISSN: 0873-626X 


\title{
Self-Evidence and A Priori Moral Knowledge
}

\author{
Elizabeth Tropman \\ Colorado State University
}

BIBLID [0873-626X (2012) 33; pp. 459-467]

\begin{abstract}
According to rationalists about moral knowledge, some moral truths are knowable a priori. Rationalists often defend their position by claiming that some moral propositions are self-evidently true. Copp 2007 has recently challenged this rationalist strategy. Copp argues that even if some moral propositions are self-evident, this is not enough to secure rationalism about moral knowledge, since it turns out that such self-evident propositions are only knowable a posteriori. This paper considers the merits of Copp's challenge. After clarifying the rationalists' appeal to self-evidence, I show why this rationalist strategy survives Copp's challenges to it.
\end{abstract}

\section{Keywords}

Moral knowledge, self-evidence, a priori, a posteriori, David Copp.

Rationalists about moral knowledge maintain that some moral truths are knowable a priori. Audi 2004 and Shafer-Landau 2003 have recently defended rationalism by appealing to the possibility of selfevident moral truths. Through a series of innovative arguments, Copp 2007 has challenged this rationalist strategy. Copp alleges that even if some moral propositions are self-evident, this is not enough to secure rationalism about moral knowledge, since it turns out that such selfevident propositions are only knowable a posteriori. This argument represents an important piece of Copp's overall project, which is to develop and defend an empiricist model of moral knowledge. In what follows, I clarify Copp's challenge and argue that it does not threaten the aforementioned rationalist strategy. This discussion will also go some way towards clarifying the appeal to self-evidence as it figures in recent defenses of moral rationalism. 


\section{A Priori Moral Knowledge}

As Audi conceives of it, a proposition is self-evident just in case it is a truth such that an adequate understanding of it satisfies the following conditions:

(a) in virtue of having that understanding, one is justified in believing the proposition (i.e., has justification for believing it, whether one in fact believes it or not); and (b) if one believes the proposition on the basis of that understanding of it, then one knows it. (Audi 1999: 206)

Self-evidence attaches to those propositions that we can know, or justifiably believe, solely on the basis of understanding them adequately. ${ }^{1}$ W. D. Ross's principles of prima facie duty, such as the principle that promise-keeping is prima facie required, are plausible candidates for self-evident truths. Once one adequately understands what the Rossian principle about promise-keeping says, it seems that this understanding is all one needs to know or justifiably believe it, provided that the belief is held on the basis of this understanding and not on some other ground. Because one's adequate understanding of a self-evident truth is sufficient to be justified in believing it, knowledge of self-evident truths, when grounded in this understanding, appears independent of experience in a way that qualifies it as a priori. It is precisely this latter point that Copp denies.

Although Copp has some reservations about the above characterization of self-evidence, his amendments to Audi's formulation are minor, and Copp (2007: 95, 100) is explicit that his arguments do not turn on a dispute about the proper conditions for self-evidence. His points are supposed to go through against the rationalists' own conception of self-evidence. Copp's ultimate conclusion is that, even if some moral propositions are self-evident, it does not follow that they are knowable a priori. To defend this point, Copp (2007: 97) appeals to Field's account of an a priori proposition. On this view, a proposition is weakly a priori just in case it 'can be reasonably believed without empirical evidence' (Field 2000: 117). This is contrasted with a proposition that is strongly a priori. A proposition is strongly a

\footnotetext{
${ }^{1}$ It is strange to speak of understanding propositions. It seems more correct to say that we understand sentences, not propositions. Understanding sentences may indeed involve grasping the propositions they express.
} 
priori just in case it is both weakly a priori and also admits of no empirical evidence against it. Copp understands an 'a priori proposition' in epistemic terms, that is, as a proposition that is knowable, or justifiably believed, a priori.

Copp's target is not weakly a priori moral knowledge. For his considered view is that once you have adopted a certain moral point of view, you do not need empirical evidence to reasonably believe those moral principles rationalists take to be a priori knowable (see Copp 2007: 45-46, 98). ${ }^{2}$ Since Copp is willing to grant that the disputed moral propositions are a priori in this weak sense, his disagreement with moral rationalists concerns the possibility of strongly a priori moral knowledge. When formulating his preferred moral empiricist position, the a posteriori is not contrasted with the weakly a priori; empirically knowable propositions are to be those that are empirically defeasible, i.e., not strongly a priori (see Copp 2007: 42-43, 98). In what follows, I shall understand propositions that are a priori to be those that are strongly a priori in the above sense. While a rationalist could question this way of distinguishing the a priori from the a posteriori, I think that Copp's arguments fail for deeper and more interesting reasons.

We should note that, for Copp, the disagreement between rationalists and empiricists also does not concern the possibility of a priori knowledge of analytic moral truths, since empiricists should, in his view, grant that analytic moral truths are knowable a priori. As Copp (2007: 97) conceives of it, a proposition is analytic just in case it is a conceptual truth. ${ }^{3}$ For instance, the proposition that murder is wrong

\footnotetext{
${ }^{2}$ I say that this is his considered view, because he also suggests that self-evident truths may not even be weakly a priori, since empirical evidence might be needed to understand adequately, and reasonably believe, self-evident propositions (2007: 104-105). Yet, this point would represent a misunderstanding of the rationalist view, for the experiences implicated in acquiring understanding do not represent evidence that the proposition is true.

${ }^{3}$ It is clear that Copp does not adopt Boghossian's epistemic notion of analyticity, according to which a statement is analytic 'provided that grasp of its meaning alone suffices for justified belief in its truth’ (Boghossian 1996: 363). Indeed, Copp believes that some non-analytic, synthetic statements are self-evident, in the sense that adequately understanding them is sufficient for justified belief in their truth, and this position does not square well with Boghossian's epistemic reading of analyticity. For Copp, what distinguishes analytic statements from synthetic ones is that analytic statements are true in virtue of inclusion relations among concepts.
} 
is plausibly analytic, insofar as the concept of murder just is the concept of wrongful killing (Copp 2007: 40). Hence, Copp needs to argue that the relevant self-evident principles are either analytic or synthetic but only knowable a posteriori. Copp pursues the second strategy.

\section{The Argument for Empirical Defeat}

The problem for rationalism is that self-evident (synthetic) moral propositions allegedly fail the empirical indefeasibility condition for being knowable a priori. Copp uncovers two ways in which our justification for believing self-evident truths can be subject to empirical defeat. He appeals to a particular moral theory, society-centered theory, to illustrate the first sort of defeater. According to societycentered theory, morality is relative to a society and its authoritative moral codes. A moral code is authoritative just in case its currency in the given society would best enable the society to meet its needs, such as the need for physical continuity, internal harmony, and cooperation with neighbors (Copp 2007: 110). An action is morally wrong in a society just in case the society's authoritative moral code forbids it.

Supposing that society-centered theory is true, Copp considers the proposition that torture is wrong. He quickly observes that any belief that torture is wrong would admit of empirical evidence against it (2007: 111). If a society's authoritative moral code does not rule out torture, this would be evidence that the proposition is not true. Such evidence is empirical, since the matter of how best to meet societal needs is an empirical one (2007: 18, 70). This point is supposed to generalize. No synthetic moral proposition - self-evident or otherwise - is knowable a priori, since any knowledge of it would be empirically defeasible in this way.

Unfortunately, if the society-centered theory is correct, the proposition that torture is wrong is not self-evident. Self-evident propositions are truths that we can know on the basis of adequately understanding them. As Copp has described it, it seems likely that the torture proposition is false in the given society. Even if the proposition were true and only possibly false, this would not help Copp's case. Since the proposition's truth-conditions depend on whether 
torture enables a society to meet its needs, as Copp has already illustrated, adequately understanding the proposition is not sufficient to know it.

For his arguments to succeed, Copp would have to claim that, even though the wrongness of torture depends on how well the practice enables a society to meet its needs, one could know that torture is wrong, if it is, solely on the basis of adequately grasping the proposition that it is. Copp (2007: 106-107) appeals to an account of moral learning to support this suggestion. According to this account, we acquire moral concepts by considering paradigmatic examples of the concepts in question. If a person acquired the concept of morally wrong by learning that torture is an example of wrong conduct, perhaps the person could know the correct moral status of torture solely on the basis of adequately grasping the proposition that torture is morally wrong.

Yet, simply because a particular moral example might have been used to demonstrate a moral concept in one's moral learning process, this does not mean that one can come to know that the example falls under the concept simply on the basis of adequately grasping the relevant proposition. In Copp's example, it is not my understanding of what the proposition says that justifies me in believing it, if I am justified. Torture might become morally required if a society's needs change, and this is why merely understanding the statement is not enough to know it. To be justified in believing that torture is wrong, I should have some sort of evidence concerning the content of my society's moral code and torture's relation to it. So far, Copp has yet to isolate an example of a proposition that is self-evident, in the sense described by Audi and Shafer-Landau, and is only knowable a posteriori.

It would seem that almost any substantive moral proposition would fail to be self-evident, on a society-centered view. In fact, the only plausible candidates for self-evident truths on this moral theory would be the most general claims about basic conditions for right and wrong, e.g., 'An action is morally wrong just in case it is ruled out by a society's code whose currency allows a society to meet its needs best.' Copp never discusses our knowledge of this sort of moral proposition. These moral propositions would not admit of the sort of empirical counterevidence described above, since their truthconditions are not tied to facts about a society's needs. It seems that such propositions, if true, would be knowable a priori. Copp might 
reply that these general moral propositions are analytic. It is not obvious, though, that this is so. Such general moral propositions have no less a claim to being synthetic than do the Rossian principles that rationalists invoke.

Perhaps the society-centered general propositions are empirically defeasible in some other way. Copp (2007, ch.1) has suggested an alternative argument for the empirical defeasibility of all synthetic moral propositions, one that does not depend on the society-centered view. This second argument concerns moral disagreement. Suppose that person $\mathrm{S}$ believes some synthetic moral proposition $\mathrm{m}$ to be true, and suppose further that $\mathrm{S}$ is aware that another person $\mathrm{P}$ disagrees; $\mathrm{P}$ believes $\mathrm{m}$ to be false. According to Copp (2007: 48-53), if S lacks an independent reason to suppose that he is in a better epistemic position with respect to m's truth, S's justification for believing $\mathrm{m}$ has been empirically undermined or defeated. Because any synthetic moral proposition can be subject to disagreement in this way, and disagreement is an empirical phenomenon, such propositions again fail to be empirically indefeasible.

The problem, as Copp is well aware, is that this argument proves too much. Propositions that we suppose are knowable a priori, such as those concerning mathematical truths, are also possibly subject to disagreement. Copp therefore proposes the following qualification: disagreement would not count as an empirical defeater if disagreement would 'not undermine the credibility of the proposition to an "ideal thinker" - a thinker with no psychological weaknesses, with no computational limitations, and with a full conceptual repertoire' (2007: 44-45). Copp suggests that disagreement over the truths of mathematics is not an empirical defeater, since such disagreement would not undermine an ideal thinker's knowledge of them. Yet, because the relevant moral propositions are synthetic rather than analytic, an ideal knower's conceptual competence is not supposed to be enough to block disagreement's undermining effects in the moral case. This means that disagreement would render our knowledge of the relevant self-evident moral propositions empirically defeasible, and hence, a posteriori.

First, I do not share Copp's intuition that, simply because a proposition is synthetic, i.e., not a conceptual truth, an ideal thinker's knowledge of it would be defeated in the face of disagreement. But more importantly, even if Copp's arguments go through, he has failed to establish his intended point, namely, that self-evident moral propo- 
sitions are not knowable a priori. Rather, what he has shown is that the moral propositions in question are not self-evident after all. Recall that the reason why the target moral propositions are not supposed to knowable a priori is that our justification for believing them can be defeated by the empirical facts of moral disagreement. The problem is that if disagreement would remove one's justification for believing the moral proposition upon understanding it adequately, then it is not the case that such understanding is sufficient for justification. That is to say, the proposition fails to meet the conditions for being self-evidently true. Copp's options here are two-fold: he could either deny that any relevant propositions are self-evident or dispute the operative characterization of self-evidence. The strength of Copp's argument is that it is not supposed to depend on any such moves.

\section{Self-Evidence and Defeasible Justification}

As Copp (2007: 105) himself acknowledges, rationalists such as Audi and Shafer-Landau readily admit that one's justification for believing self-evident truths is not indefeasible. ${ }^{4}$ It is instructive, in closing, to compare the sense in which rationalists think that one's knowledge of self-evident truths is subject to defeat to the discussion above.

Rationalists stress that, even though one's adequate understanding of a self-evident proposition is sufficient to justify one's belief in it, it does not follow that one will believe it on the basis of this understanding. One could withhold belief or believe a self-evident proposition on the basis of another, inadequate ground, such as unreliable testimony. Additionally, further considerations could undermine or cloud one's previously adequate understanding of the proposition. Indeed, becoming aware of persistent moral disagreement could lead to any one of these results. While an adequate understanding of a selfevident proposition is always sufficient to justify one's belief in it, it is possible to lose this justification if one loses the relevant understanding or fails to base one's belief on the good grounds that one has. In these ways, rationalists can allow that possessing counterevidence

\footnotetext{
${ }^{4}$ For a fuller discussion of these matters, see Audi (1999: 219-221) and Shafer-
} Landau (2003: 256-258). 
may defeat one's knowledge of a self-evident truth. Still, it is unlikely that this sort of defeasibility would be enough to disqualify knowledge of self-evident truths as a priori. If it is, rationalists should reject such an indefeasibility condition for a priori knowledge.

\section{Conclusion}

Despite the ingenuity of Copp's arguments, I have claimed that they do not succeed. Not only does Copp's defense of empiricism likely rely on its own class of a priori moral knowledge, he has failed to isolate a relevant self-evident moral proposition that is only knowable a posteriori; either the proposition in question is not self-evident, or, if it is, our beliefs in it can satisfy the conditions for a priori knowledge.

One lesson here is that a more promising tactic against rationalism is to be found among the avenues Copp does not pursue: showing that the relevant moral propositions, such as Ross's principles of prima facie duty, are either analytic or not self-evident. Regarding the first option, it is not obvious that Ross's principles are analytic, in the sense of being true in virtue of containment relations among concepts. If Ross's principles are analytic according to some other notion of analyticity, the burden is on the empiricist to explain why being analytic - however understood - is a problem for rationalism about moral knowledge. Regarding the second option, if it turns out that Ross's principles are not proper candidates for self-evident truths, it remains to be seen how an alternative conception of moral knowledge, e.g., one that is grounded in Copp's society-centered view, can itself avoid appealing to some other self-evidently true moral principle. In the meantime, Copp's arguments aside, we should conclude that establishing a class of self-evident moral propositions remains a sound strategy for rationalism. ${ }^{5}$

$$
\begin{array}{r}
\text { Elizabeth Tropman } \\
\text { Department of Philosophy } \\
\text { Colorado State University }
\end{array}
$$

\footnotetext{
${ }^{5}$ I am grateful to two anonymous referees for their comments and suggestions, and to Michael Losonsky for helpful discussions on the topic.
} 


\section{References}

Audi, Robert. 1999. Self-Evidence. Philosophical Perspectives 13: 205-228.

Audi, Robert. 2004. The Good in the Right: A Theory of Intuition and Intrinsic Value. Princeton: Princeton University Press.

Boghossian, Paul. 1996. Analyticity Reconsidered. Nous 30: 360-391.

Copp, David. 2007. Morality in a Natural World: Selected Essays in Metaethics. Cambridge: Cambridge University Press.

Field, Harty. 2000. Apriority as an Evaluative Notion. In New Essays on the A Priori, edited by Paul Boghossian and Christopher Peacocke. Oxford: Clarendon Press, 117-149.

Shafer-Landau, Russ. 2003. Moral Realism: A Defense. Oxford: Clarendon Press. 